\title{
Linguagem, hermenêutica e atividade epistemológica na Educação Física
}

\author{
Paulo Evaldo Fensterseifer ${ }^{*}$
}

\begin{abstract}
Resumo: O presente texto busca trazer para a comunidade científica da Educação Física um conjunto de notas referentes à temática da linguagem tal como entendida pela Hermenêutica Filosófica. A consideração deste referencial nos possibilita redimensionar a questão do conhecimento, visto que implica uma inflexão no entendimento da racionalidade hegemônica na filosofia ocidental com suas devidas implicações para os diferentes campos do saber, entre eles, um redimensionamento da atividade epistemológica.

Palavras-chave: Linguagem. Hermenêutica. Epistemologia. Educação Física.
\end{abstract}

O mundo se tornou mais uma vez 'infinito' para nós, porque ele contém em si a possibilidade de interpretações infinitas.(Nietzsche)

Este ensaio tem como propósito enfatizar a contribuição de um referencial que acredito capaz de fomentar o debate no interior da Educação Física e, em particular, no que tange ao debate epistemológico, partindo do tema da linguagem tal como entendido pela hermenêutica filosófica. Cabe explicitar, em um primeiro momento, as origens do termo hermenêutica. Utilizo para isto a explicitação sucinta de Ruedell (2005, p. 224), segundo o qual,

as raízes do termo hermenêutica encontram-se no verbo grego hermeneuein, usualmente traduzido por interpretar, e no substantivo hermeneia, interpretação. O estabelecimento e o uso dessas palavras, por sua vez, remetem à mitologia grega, mais precisamente, a Hermes, deus mensageiro. Hermes associase à transmutação, à transformação de tudo o que está acima da compreensão humana, tornando-se acessível à inteligência humana. Enquanto mensageiro

* Professor do Departamento de Pedagogia da Universidade Regional do Noroeste do Estado do Rio Grande do Sul (Unijuí). ljuí, RS. E-mail: fenster@unijui.edu.br 
divino, traz aos homens a mensagem do mundo dos deuses, a anuncia e a torna compreensível; aproxima e explica o que era distante e obscuro.

Já a hermenêutica filosófica caracteriza-se, segundo Ruedell (2005), por não ter sua preocupação centrado no como, não é, portanto, uma técnica e não fornece também orientações para a interpretação. Segundo o autor, baseado em Scholtz, a hermenêutica filosófica

apenas visa compreender o que torna possível a interpretação e a compreensão, em outras palavras, pergunta pelas condições de possibilidade da compreensão (RUEDELL, 2005, p. 226-227).

Visualizo neste referencial, e em particular no tema da linguagem, uma capacidade de inspiração para pensarmos as questões do conhecimento sob uma perspectiva ainda pouco explorada em nosso âmbito. ${ }^{1}$ Este interesse funda-se no entendimento de Fensterseifer (1999, p. 173) de que "são as formas discursivas que nos interessam na atividade epistemológica". Logo,

a tarefa primeira da crítica epistemológica é a tematização da linguagem como 'medium' de produção de significações. É ela (linguagem) o nosso meio de acesso, não o ser, mas o discurso sobre o ser. ${ }^{2}$

Aceita esta prerrogativa, penso que não é possível a atividade epistemológica sem o recurso da linguagem, uma vez que, concordando com Berticelli (2004, p. 89), "a experiência do mundo se traduz como linguagem. Não há outra tradução possível da experiência do mundo que não seja a linguagem". Nas palavras de Gadamer, "a peculiar objetividade do mundo decorre da relação da linguagem com ele" (apud BERTICELLI, 2004, p. 88, nota 4, grifos do autor).

Enfatizando ainda o lugar da linguagem trago a contribuição de Palmer (1989, p. 20-21), segundo o qual

\footnotetext{
${ }^{1}$ Exercício, neste sentido, podemos encontrar no texto Corpo e linguagem (FENSTERSEIFER, 2004). No âmbito da educação sugiro a leitura de Hermann (2002) e Berticelli (2004).

$2 \mathrm{O}$ que, depois de Kant, não deve significar limite no sentido negativo, mas a própria condição do conhecer humano. Também cabe observar que medium ou meio neste contexto não significa instrumento, aproximando-se mais da noção que temos de meio-ambiente.
}

Movimento, Porto Alegre, v. 15, n. 04, p. 243-256, outubro/dezembro de 2009. 
a existência humana tal como a conhecemos implica
sempre a linguagem e assim, qualquer teoria sobre a
interpretação humana tem que lidar com o fenôme-
no da linguagem. E entre os mais variados meios
simbólicos de expressão usados pelo homem, ne-
nhum ultrapassa a linguagem quer na flexibilidade e
poder comunicativos, quer na importância geral que
desempenha. A linguagem molda a visão do homem
e o seu pensamento - simultaneamente a concep-
ção que ele tem de si mesmo e do seu mundo (não
sendo estes dois aspectos tão separados como pa-
recem). A própria visão que tem da realidade é mol-
dada pela linguagem [...]. Se considerarmos este tema
em profundidade, torna-se visível que a linguagem
é o "médium" no qual vivemos, nos movemos e no
qual temos o nosso ser.

O sentido dado aqui à hermenêutica pressupõe esta centralidade da linguagem, fenômeno que produz na filosofia o que denominamos giro linguístico, virada linguística ou ainda linguistic turn, o que, resumidamente, significa o deslocamento da questão da razão e da verdade do plano da relação sujeito-objeto para o plano da linguagem. Com isto, coloca o problema da interpretação no centro das preocupações filosóficas, ${ }^{3}$ o que implica um rompimento com a concepção do conhecimento como representação de uma consciência individual. Inflexão do pensamento filosófico contemporâneo que terá no acontecer intersubjetivo da linguagem seu fundamento de validação. Da mesma forma, a validação científica já não se dá como

evidência para uma consciência individual, senão principalmente, em virtude de seu reconhecimento público como paradigma de um jogo linguístico (no sentido de Wittgenstein) (APEL apud BERTICELLI, 2004, p. 95-96).

Espero, no conjunto das notas que seguem, repercutir as implicações desta postura que alicerçam o que tem se chamado de pensamento pós-metafísico.

\footnotetext{
${ }^{3} \mathrm{Na}$ definição de Gadamer, "a hermenêutica é isto: saber o quanto fica, sempre, de não dito quando se diz algo" (apud HERMANN, 2002, p. 72).
}

Movimento, Porto Alegre, v. 15, n. 04, p. 243-256, outubro/dezembro de 2009. 
1. O abandono do esforço para conhecer a coisa em si, já assumido por Kant, retira da ontologia a pretensão de esgotar o sentido do ser através do conhecimento do efetivamente existente, contentando-se em apreender o sentido do ser enquanto sendo, o que se dá linguisticamente. Daí a afirmação de Gadamer: ser que pode ser compreendido é linguagem. Constituindo-se a linguagem em depositária da historicidade do ser, o qual é indissociável do tempo (proposição heideggeriana encarnada no título da obra Ser e Tempo).

2. A linguagem não é produto (ergo), mas atividade (energia), na qual se efetiva toda compreensão. Compreensão que não é uma faculdade do humano, mas o próprio modo de ser do ser-aí (Dasein). Abertura que se dá sempre como interpretação, originando as distintas formas discursivas constituidoras de mundos (mítico, religioso, científico...). Produtividade que se expressa também nos conhecimentos disciplinares capazes de fundar comunidades argumentativas e de produzir intervenções nos diferentes campos (natural, social, estético).

3. A linguagem mantém-se aberta em sua dinamicidade ("só se conserva enquanto se transforma" - LARROSA, 2002), em função de seu vínculo com a historicidade da condição humana, bem como ao seu caráter inerentemente babélico. Esta condição tem demandado esforços no sentido de coisificar, objetivizar, instrumentalizar a linguagem por parte dos estados nacionais, linguistas, filósofos etc. O que se traduz em línguas nacionais, regras, conceitos etc., em uma tentativa interminável de homogeneização da língua, que tem como telos, segundo Larrosa (2002), a pretensão de que "as palavras digam a mesma coisa" e que "o discurso possa controlar o discurso". Como, no entanto, conceitos e discursos são compostos de palavras, e estas, "embora permaneçam as mesmas, nunca dizem a mesma coisa" (POZCHIA apud LARROSA, 2002), nunca superamos a imprecisão essencial do conhecer, pois este depende da linguagem, uma vez que a "realidade 'mesma' não fala de si, tem necessidade de um porta-voz" (VATTIMO, 2001, p. 43). E este usa para isso uma "ferramenta imperfeita" (HENRY, 1992), ou, em termos hermenêuticos, é usado por ela. Logo, a linguagem é inalcançável para nós, seres finitos. Em torno deste esforço de superar o caos das línguas históricas, Merleau-Ponty (2002, p. 25) faz a seguinte afirmação:

Movimento, Porto Alegre, v. 15, n. 04, p. 243-256, outubro/dezembro de 2009. 
O algoritmo, o projeto de uma língua universal, é a revolta contra a linguagem dada. Não se quer depender de suas confusões, quer-se refazê-la à medida da verdade, redefini-la segundo o pensamento de Deus, recomeçar do zero a história da fala, ou melhor, arrancar a fala à história.

4. A linguagem, segundo Humboldt, é humana desde seu começo (apud GADAMER, 1999, p. 642). Origina-se com a consciência e a sociedade. Juntas, estão sujeitas, ao vir-a-ser, à história, logo, não são um dado, um fato natural (GIACÓIA JÚNIOR, 2001, p. 40). Não havendo, portanto, mundo humano anterior à linguagem ou sem linguagem, pois este (o mundo) constitui-se linguisticamente. Mundo que é solo comum dos que falam entre si, não se constituindo em barreira ao conhecimento, mas em possibilidade de que algo possa elevar-se a nossa percepção, pois "o que se representa é sempre um mundo humano, isto é, estruturado linguisticamente, seja lá qual for a sua tradição" (GADAMER, 1999, p. 648-649).

5. Dado que a linguagem nos ultrapassa, "como seres finitos sempre vimos de muito antes e chegamos até muito depois". Nela "torna-se claro o que é real, mais além da consciência de cada um" (GADAMER, 1999, p. 652). No acontecer linguístico põe-se a descoberto o todo do nosso comportamento, seja o das verdades narradas pela ciência, seja o universo das aparências (mesmo depois de Copérnico o sol continua se pondo). Nesse acontecer "tem lugar não somente o que se mantém, mas também e justamente a mudança das coisas" (GADAMER, 1999). Exemplifica-se esta mudança na decadência das palavras que podem revelar mudan-ças nos costumes e nos valores.

6. A relação fundamental de linguagem e mundo não significa que o mundo se torne objeto da linguagem (GADAMER, 1999, p. 653). Ter linguagem significa ter um mundo, este porém não é um em $s i$, uma vez que não é objeto, e isto, por uma razão fundamental: "não existe nenhum lugar fora da experiência linguística do mundo a partir do qual este pudesse converter-se a si mesmo em objeto" (GADAMER, 1999, p. 657). Logo, a objetividade da linguagem (Sachlichkeit) não é a mesma objetividade da ciência (Objektivität), que conhece leis, "tem algo em suas mãos” (GADAMER, 1999, p. 658). Falar, segundo Gadamer 
(1999, p. 658), "não significa, de maneira alguma, tornar coisas disponíveis, e calculáveis [...] essa experiência permanece ela mesma, entrelaçada no comportamento vital". Enquanto isso, para a ciência objetivadora, a experiência linguística do mundo encontra-se carregada de preconceitos que os métodos matematizantes precisam eliminar.

Movimentando-se no plano da linguagem, a atividade epistemológica não tem acesso ao ser das coisas (ser em si), mas aos discursos sobre o ser. Aceito, porém, a proposição heideggeriana de que a linguagem é a casa onde habita o ser. Percebemos que estes discursos não são representações do mundo, mas são mundos, não dizem do mundo, mas dizem mundos. Palmer (1989, p. 244-245) explicita este entendimento na seguinte passagem:

A linguagem de facto não é um instrumento mas sim o modo como o ser aparece. Quando queremos transmitir o ser de uma situação, não imaginamos uma linguagem que se lhe adapte mas antes encontramos a linguagem adequada à situação. Assim o que encontra expressão na linguagem não é a nossa "reflexividade" mas a própria situação: as palavras não funcionam essencialmente para se referirem a esta subjectividade; pelo contrário, referem-se à situação. O fundamento da objectividade não está na subjectividade daquele que fala mas sim na realidade que se exprime na e pela linguagem. É nesta objectividade que a experiência hermenêutica deverá encontrar o seu fundamento.

Logo, a tarefa epistemológica, orientada hermeneuticamente, não se faz apelando a referências exteriores (teológicas ou naturais), mas do interior de padrões finitos de verdade. Portanto, como lembra Hermann (2002), compreender não se dá fora de um contexto, de uma cultura, o que impossibilita pensar o fenômeno da compreensão a partir exclusivamente de estruturas lógicas, tal como propunha a epistemologia genética piagetiana. Afirma a autora que,

Compreender o pensamento humano como uma operação mental ou como uma análise lógica implica silenciar a dimensão de historicidade do homem, que se realiza no horizonte da própria linguagem. Implica, ainda, submeter a complexidade do processo de com-

Movimento, Porto Alegre, v. 15, n. 04, p. 243-256, outubro/dezembro de 2009. 
preensão e de busca de sentido à tutela das ciências lógico formais (HERMANN, 2002, p. 64).

Movimentamo-nos em um jogo de linguagem que se constitui no interior de uma tradição, a qual fornece os pressupostos da nossa compreensão. Esta percepção nos possibilita manter aberto o debate em torno das condições de possibilidades dos métodos com que operam as ciências, perguntando-nos sobre a possibilidade do conhecer, o lugar do intérprete, as condições de possibilidade do ato interpretativo etc. Atividade, enfim, que zela, no interior de uma comunidade científica para que o acontecer da verdade faça-se argumentativamente. É esta a posição de Gadamer quando afirma: "O modelo do conhecer é o diálogo e não o encontro entre um sujeito autônomo e um objeto dominado, que é o postulado da ciência moderna e também, em certo sentido, a morte da metafísica" (apud BERTICELLI, 2004, p. 69-70).

Este acontecer, entendido em sua radicalidade, dispensa esforços, ou torna problemáticas preocupações/afirmações como, por exemplo, as de Oliveira (1983, p. 105): "o que procuramos é a verdadeira natureza da Educação Física. A sua essência. Aquilo que realmente ela é". Da mesma forma a posição de Medina (1983, p. 58) que, ao desqualificar as afirmações dos sujeitos de sua pesquisa, referencia-se em uma "verdadeira educação". Em texto mais recente parece persistir "recaídas essencialistas", como as que identificamos em Crisorio (2003, p. 48-49) ao referir-se a um possível "defeito de identidade" e a "educação física como tal", para além de um certo saudosismo da "paidotribia original". 4

Manter uma perspectiva metafísica, essencialista, nos permite ter uma medida para a crítica, denunciando tudo aquilo que não é Educação Física. Se, porém, concordarmos com Larrosa (2004, p. 348) "de que a pergunta o que é? não é uma boa pergunta, ao menos se está propondo, ingenuamente, como a pergunta por uma coisa, pela identidade e pela identificação de uma coisa". Cabe, segundo o autor, descoisificar, desnaturalizar, reconhecendo o caráter de invento das instituições humanas, o que nos permite perguntar - como se constituem e como funcionam esses inventos?

${ }^{4} \mathrm{Não}$ podemos ignorar que, em alguns casos, estes entendimentos, aqui recortados, conflitam com o conjunto da obra ou pensamento dos autores.

Movimento, Porto Alegre, v. 15, n. 04, p. 243-256, outubro/dezembro de 2009. 
Uma pergunta que parece ter ficado em aberto neste debate é: por que não aplicar este raciocínio antimetafísico que aplicamos à noção de identidade, e até mesmo - ou fundamentalmente - à noção de verdade, à ciência? Por que não aplicamos aqui o que afirmávamos anteriormente a partir de Larrosa (2002) de que embora as palavras permaneçam as mesmas nunca dizem a mesma coisa? Ou ainda, como quer Merleau-Ponty (2002, p. 23), quando afirma que "nenhum pensamento permanece nas palavras, nenhuma palavra no puro pensamento de alguma coisa".

Parece que, por um lado, reservamos à ciência a condição de sparring, por outro, buscamos o reconhecimento da comunidade científica, por exemplo, filiando-nos à SBPC. Quando queremos execrar a ciência referimo-nos a ela como uma substancialidade: $a$ Ciência. Em outros momentos vangloriamo-nos em usar conceitos científicos como capital cultural (duplo sentido).

Levar a sério o referencial hermenêutico, anteriormente esboçado, significa apropriarmo-nos da noção de ciência sem, por um lado, ignorar a tradição que cerca este conceito, mas, por outro, dessacralizando-o, condição para sua ressignificação. Tenho exemplificado esta tomada de posição com a experiência do Mestrado em Educação nas Ciências, da Unijuí (Ijuí-RS), o qual, por um lado, não contém nenhuma cláusula que exclua uma área do saber por não ser ciência, e, por outro, entende a produção realizada no interior do programa como sendo científica. Postura que deriva de seu entendimento de cientificidade, a qual se vincula à noção de que algo atinge esta condição pela argumentação sustentada publicamente entre seus pares da comunidade acadêmica, os quais, por sua vez, possuem legitimidade social (prerrogativa herdada da tradição, mas que deve pelo seu exercício ser constantemente renovada). Conforme Berticelli (2004, p. 96-97),

este posicionamento leva em conta o deslocamento de uma crítica do conhecimento enquanto análise da consciência para uma crítica do conhecimento enquanto análise da linguagem. O valor de verdade já não consegue manter sua identidade com o problema da evidência ou da certeza (certitudo), como $\operatorname{diz}$ Apel, em consonância com uma consciência solitária cartesiana, nem em função de uma validez ob-

Movimento, Porto Alegre, v. 15, n. 04, p. 243-256, outubro/dezembro de 2009. 
jetiva para uma consciência em geral kantiana, mas sim em função de uma formação intersubjetiva do consenso mínimo.

Este entendimento, segundo Fensterseifer (2002), não nos permite mais pensar a epistemologia como instância legitimadora daquilo que na modernidade aspira à condição de verdade, chamando a si a responsabilidade de reconhecer o status de cientificidade de uma área do saber e zelando pelos processos metodológicos incontornáveis para garantir a objetividade dos conhecimentos produzidos. Sabemos que este lugar era assegurado pelo pressuposto da equivalência Verdade $=$ Razão $=$ Ciência, o qual tem sofrido sérios questionamentos por parte da tradição crítica aos quais acrescento os da tradição hermenêutica. Elementos tais como: interesses orientadores do conhecimento, historicidade, finitude, virada linguístico-pragmática, entre outros, nos levam, por um lado, a interrogar a pertinência da epistemologia arrogarse deste lugar privilegiado em relação à verdade e, por outro, se isto deve significar o abandono de qualquer normatização para o julgamento das pretensões de verdade.

O enfrentamento destas questões não é obviamente exclusividade nossa, mas não podemos esperar que se resolva em outro âmbito para aplicar na Educação Física. Ao contrário, ela se configura no próprio modo com que operamos ao produzirmos conhecimentos. Assim, se podemos dar razão à afirmação de $\operatorname{Vaz}(2003$, p. 119) de que é "um tanto absurdo escrever uma reflexão sobre 'metodologia da pesquisa em educação física', assim como também parece fora de propósito uma 'epistemologia da educação física"', não me parece nada absurdo ou fora de propósito romper com a noção metafísica de Razão/Verdade/Ciência, sustentando reflexões de caráter metodológico adequado aos nossos propósitos, bem como mantendo viva a atividade epistemológica a respeito dos conhecimentos produzidos no âmbito da Educação Física.

Fazendo um balanço das perspectivas epistemológicas que se apresentam no interior da Educação Física pós-crise dos anos $80^{5}$ (século

\footnotetext{
${ }^{5} \mathrm{O}$ uso da expressão "pós-crise dos anos 80" não significa necessariamente o rompimento com elementos da nossa tradição epistemológica, mas muito mais a afirmação de certas posturas diante desta crise.
}

Movimento, Porto Alegre, v. 15, n. 04, p. 243-256, outubro/dezembro de 2009. 
$\mathrm{XX}$ ), podemos visualizar entre as alternativas a herança naturalista que busca alicerçar a cientificidade da Educação Física no objetivismo cientificista, o qual crê poder traduzir o que considera relevante do movimento humano em termos lógico-formais. Esta corrente busca sua legitimidade, por um lado, na sombra do status que desfrutam as determinadas ciências duras e, por outro lado, nas contribuições inegáveis que fornece para o campo do esporte de rendimento, para o campo da saúde e do desenvolvimento motor. Legitimidade que se constrói, como é próprio desta tradição científica, ao largo das preocupações ético-políticas e, em parte, das demandas pedagógicas da Educação Física.

Contrapondo-se a esta perspectiva coloca-se a posição das correntes epistemológicas que reconhecem a historicidade da condição humana e, portanto, das dimensões ligadas a esta, tais como o movimento humano, o corpo, as práticas lúdicas etc. Este reconhecimento não significa necessariamente o abandono do objetivismo científico, mas se coloca agora vinculado ao esforço das chamadas Ciências Humanas (ou Sociais) na busca de um fundamento ontológico. Colocandose nesta empreitada a Educação Física estaria cerrando fileiras para a objetivação de um processo histórico que conduziria a humanidade à emancipação. Processo alicerçado em uma objetividade cientifica, inerente às relações sociais em que os humanos estão implicados.

Uma terceira perspectiva epistemológica deriva da fenomenologia e busca complexificar as possibilidades de objetificação de temas caros a nossa área, tais como corpo e movimento, reconhecendo as dificuldades de apreendê-las nos limites da linguagem científica, sejam elas das Ciências Naturais ou Humanas. Esta perspectiva busca maior fidelidade à natureza do seu objeto, o que, se por um lado enriquece nossa percepção sensitiva dos fenômenos que compõem nossas experiências no universo da cultura corporal, por outro pode nos conduzir à ilusão de um mergulho numa espécie de imanência sensitiva, livre de mediações, entre elas, a da linguagem.

Diante deste quadro, traçado em rápidas pinceladas, que interpretações o referencial esboçado no início deste texto nos sugere para pensarmos a responsabilidade pedagógica da Educação Física?

Movimento, Porto Alegre, v. 15, n. 04, p. 243-256, outubro/dezembro de 2009. 
A hermenêutica não descarta a pretensão de objetividade das ciências (naturais ou humanas), mas não tem ilusões de que elas esgotem o sentido dos temas/objetos sobre os quais anuncia suas conclusões. Reconhece no método científico um potencial explicativo e funcional extremamente engenhoso, porém não ignora que suas possibilidades são parciais, e nisso não vai nenhum demérito. Esse limite (sem sentido pejorativo) nos impede de derivar desse conhecimento uma normatividade ético-política, e nisso evidencia sua insuficiência para configurar um projeto pedagógico no interior de uma sociedade plural. De sua episteme não se faz possível derivar saídas para o campo educacional e, em particular, para a Educação Física, que dispensa os sujeitos envolvidos nesse espaço, o que significa o abandono de projetos orientados por uma vanguarda esclarecida que sabe antes e melhor que o povo o que é bom para o povo.

Também podemos, a partir da hermenêutica, suspeitar dessa pretensa primazia dos sentidos como capaz de constituir um mundo humano sem as mediações da linguagem. Se este esforço já é questionável no próprio exercício das vivências corporais, uma vez que mesmo antes de nascer pertencemos a um mundo simbólico constituído no interior de uma cultura, mais problemático ainda seria acreditar que dessa experiência originária pudéssemos derivar um projeto pedagógico para a Educação Física enquanto componente curricular responsável pela sistematização de um determinado conhecimento acerca da cultura corporal de movimento.

Cabe, por fim, diante das contribuições da hermenêutica, interrogar a respeito das condições de possibilidade da atividade epistemológica em um tempo em que emergem novos sentidos para pensarmos a objetividade dos conhecimentos e da própria noção de verdade. Penso aqui nos termos que o tema da objetividade assume em uma perspectiva hermenêutica, fundando-se não "na subjetividade daquele que fala, mas sim na realidade que se exprime na e pela linguagem. É nesta objetividade que a experiência hermenêutica deverá encontrar o seu fundamento" (PALMER, 1989, p. 244-245). Tarefa que, dado seu caráter não-dogmático, convoca todos ao diálogo. Diálogo que só faz sentido à medida que as verdades reificadas são abolidas e o relativismo não seja a nossa opção, restando a frágil certeza de um pensamento pós-

Movimento, Porto Alegre, v. 15, n. 04, p. 243-256, outubro/dezembro de 2009. 
metafísico que tem na intersubjetividade dos sujeitos implicados em diferentes contextos sua legitimidade e para o qual o fundamento é o argumento.

Movimento, Porto Alegre, v. 15, n. 04, p. 243-256, outubro/dezembro de 2009. 


\begin{abstract}
Language, hermeneutics and epistemologic activity in Physical Education

Abstract: The present text aims to bring for the scientific community of the Physical Education a set of referring notes to thematic of language such as understood by philosophical hermeneutics. The consideration of this reference makes possible to review the question of knowledge since it implies an inflection in the hegemonic rationality agreement in the western philosophy with its due implications to the different fields of knowing, between them, a review of the epistemological activity.

Keywords: Language. Hermeneutics. Epistemology. Physical Education.
\end{abstract}

Hermenéutica e actividad epistemológica em la
Educación Física
Resumen: El presente texto busca traer para la comuni-
dad científica de la Educación Física un conjunto de no-
tas referentes a la temática del lenguaje tal como enten-
dido por la hermenéutica filosófica. La consideración
de este referencial nos posibilita redimensionar las cues-
tiones del conocimiento en el momento que implica una
inflexión en el entendimiento de racionalidad hegemónico
en la filosofía occidental con sus debidas implicaciones
para los diferentes campos del saber, entre eles, un re-
dimensionamiento da actividad epistemológica.
Palabras clave: Lenguaje. Hermenéutica. Epistemología.
Educación Física.

\title{
REFERÊNCIAS
}

BERTICELLI, Ireno Antônio. A origem normativa da prática educacional na linguagem. ljuí: Ed. da Unijuí, 2004

CRISORIO, Ricardo. Educação Física e identidade: conhecimento, saber e verdade. In: BRACHT, V.; CRISORIO, R. (Coord.). A Educação Física no Brasil e na Argentina: identidade, desafios e perspectivas. Campinas, SP: Autores Associados, 2003.

FENSTERSEIFER, Paulo E. Conhecimento, epistemologia e intervenção. In: GOELLNER, Silvana Vilodre (Org.). Educação Física/ciências do esporte: intervenção e conhecimento. Florianópolis, 1999. p.171-183.

Corpo e linguagem. In: STREY, M. N.; CABEDA, S. T. L. (Org.). Corpos e subjetividades em exercício interdisciplinar. Porto Alegre: EDIPUCRS, 2004. p.289-301.

Movimento, Porto Alegre, v. 15, n. 04, p. 243-256, outubro/dezembro de 2009. 
. Atividade epistemológica e Educação Física. In: I COLÓQUIO BRASILEIRO SOBRE EPISTEMOLOGIA E EDUCAÇÃO FÍSICA, 2002, Natal (mimeo).

GADAMER, Hans-Gerg. Verdade e método. Petrópolis, RJ: Vozes, 1999.

GIACOIA JÚNIOR, Oswaldo. Nietzsche como psicólogo. São Leopoldo, RS: Ed. da Unisinos, 2001.

HERMANN, Nadja. Hermenêutica e educação. Rio de Janeiro: DP\&A, 2002.

HENRY, Paul. A ferramenta imperfeita: língua, sujeito e discurso. Campinas, SP: Ed. da Unicamp, 1992.

LARROSA, Jorge. Educação, linguagem e diferença. Seminário proferido em ljuíRS, em maio de 2002. 2004.

Linguagem e educação depois de Babel. Belo Horizonte: Autêntica,

MEDINA, João Paulo Subirá. A Educação Física cuida do corpo... e Mente. Campinas, SP: Papirus, 1983.

MERLEAU-PONTY, Maurice. A prosa do mundo. São Paulo: Cosac \& Naify, 2002.

OLIVEIRA, Vitor M. de. O que é Educação Física. São Paulo: Brasiliense, 1983.

PALMER, Richard E. Hermenêutica. Lisboa: Edições 70, 1989.

RUEDELL, Aloísio. Hermenêutica. In: GONZÁLEZ, F. J.; FENSTERSEIFER, P. F. Dicionário crítico de Educação Física. ljuí: Ed. da Unijuí, 2005.

VATTIMO, Gianni. A tentação do realismo. Rio de Janeiro: Lacerda Editores; Instituto Italiano di Cultura, 2001.

VAZ, Alexandre. Metodologia da pesquisa em Educação Física: algumas questões esparsas. In: BRACHT, V.; CRISORIO, R. (Coord.). A Educação Física no Brasil e na Argentina: identidade, desafios e perspectivas. Campinas, SP: Autores Associados, 2003.

Recebido em: 29.09.2008

Aprovado em: 02.07.2009

Movimento, Porto Alegre, v. 15, n. 04, p. 243-256, outubro/dezembro de 2009. 